\title{
Das ilusões do real às verdades da fantasia: configurações da psicologia infantil em $A$ bicicleta que tinha bigodes, de Ondjaki
}

From the illusions of the real to the truths of the fantasy: child psychology configurations in A bicicleta que tinha bigodes, by Ondjaki

\author{
Fabio Gustavo Romero Simeão \\ UFPB \\ Vanessa Riambau Pinheiro
}

UFPB

\begin{abstract}
Resumo
Pretendemos, no presente artigo, realizar uma leitura de A bicicleta que tinha bigodes (2013), romance infanto-juvenil de Ondjaki. Confrontadas, por um lado, com problemas "externos", relativos à precária situação socioeconômica do seu país, que, na altura dos eventos narrados na obra em questão, encontrava-se em meio a uma violenta guerra civil, e, por outro, com problemas "internos", de ordem mais psicológica e afetiva, as crianças imaginadas por Ondjaki conseguem representar a complexa psicologia infantil. É precisamente esse último aspecto que a nossa análise irá privilegiar, ao escolher como chave de leitura a construção psicológica de algumas das personagens principais. Pretendemos, dessa forma, examinar a representação do universo psicológico infantil no referido romance, em especial quando este é confrontado com a psicologia adulta. Para tanto, recorremos, principalmente, ao aparato teórico da psicanálise, mas também nos servimos de algumas considerações de ordem socio-histórica, imprescindíveis para compreensão integral do corpus elencado.

Palavras-chave: literatura infantil angolana; psicanálise; A bicicleta que tinha bigodes
\end{abstract}

\section{Abstract}

In this paper, we intend to do a reading of A bicileta que tinha bigodes (2013), by Ondjaki, Angolan writer. Faced, on the one hand, with "external" problems relating to the precarious socioeconomic situation of his country, which, at the time of the events narrated in the work in question, was in in the midst of a violent civil war, and, on the other hand, with "internal" problems of a more psychological manner, the children imagined by Ondjaki capture some of the most complex inner workings of infantile psychology. It is precisely this last aspect that our analysis will privilege, by choosing as a reading key the psychological construction of some of the main characters. In this way, we intend to examine the representation of the children's psychological structure in said novel, especially when it is confronted with adult psychology. For this, we resorted mainly to the theoretical apparatus of Psychoanalysis, but also to some sociohistorical considerations, indispensable for a more holistic understanding of our corpus. 
Keywords: Angolan children's literature; Psychoanalysis; A bicileta que tinba bigodes (2003)

\section{Introdução}

Se é verdade que o estudo da literatura infantil ainda hoje é visto por uma parcela considerável da sociedade - e, infelizmente, nos circuitos acadêmicos não é diferente - com certa desconfiança e desdém, também é verdade que, pelo menos desde meados da década de 1970, o interesse científico sobre esse campo vem aumentando exponencialmente ${ }^{1}$. Surgem, nessa seara, investigações de natureza múltipla, desde aquelas de teor mais historiográfico, que se interessam pela gênese e desenvolvimento do gênero; outras de feição mais crítica, preocupadas em analisar, sempre fundamentadas em discussões teóricas rigorosas, aspectos formais e/ou temáticos levantados por esse tipo de textos; até, inclusive, estudos de cunho mais pedagógico, que exploram as diversas relações entre a literatura infantil e a educação.

Em se tratando de uma área de pesquisa que, não raro, é (des)caracterizada como simples, banal ou até mesmo dispensável, consideramos de suma importância a produção e divulgação de trabalhos que tomem como seu objeto de estudo títulos da literatura dita "infantil", no intuito de combater preconceitos profundamente arraigados tanto no imaginário leigo quanto no erudito. Sendo assim, acreditamos que a análise sistemática dessa tradição literária, que, segundo alguns pesquisadores ${ }^{3}$, remonta à cultura popular que floresceu na Europa da Idade Média, pode configurar-se como um espaço de debate bastante proveitoso, especialmente para o futuro professor de língua portuguesa.

Para esse profissional em particular, o conhecimento teórico sobre literatura infantil, aliado a um repertório de leitura heterogêneo e democrático e o domínio de técnicas para a mediação da leitura literária permitem o desenvolvimento de uma prática pedagógica que, diferente do que habitualmente observamos em salas de aula, não reduza o texto literário a um simples "pré-texto" para o ensino de língua, mas, pelo contrário, consiga aproveitar a natureza polissêmica que a literatura possui para alcançar aquilo que Antonio Candido ${ }^{4}$ chamou de "humanização do ser humano", isto é, a "confirmação do homem na sua humanidade".

Isto posto, pretendemos, no presente artigo, realizar uma leitura de $A$ bicicleta que tinha bigodes. A narrativa em tela, situada em um bairro pobre na periferia de Luanda, retrata o drama de um grupo de amigos que, ao se inteirarem que a Rádio Nacional de Angola estava

1 A esse respeito, conferir Crítica, teoria e literatura infantil (2010), de Peter Hunt. Principalmente o segundo capítulo, intitulado "Situação da literatura infantil", no qual o autor desenha um panorama dos estudos mais representativos para a consolidação da literatura infantil como disciplina efetiva nas instituições de ensino superior e sua consequente introdução no cenário intelectual moderno.

2 Como muitos conceitos dentro da teoria literária, a "literatura infantil" se presta a confusões e ambivalências que dificultam uma definição única, completa. Isto posto, temos consciência de que, ao subscrevermo-nos a uma noção singular, estamos, muito provavelmente, ignorando outras possibilidades. Todavia, reservamos um pequeno espaço, no próximo tópico, para discutir algumas das concepções mais correntes.

3 Segundo Ricardo Azevedo (2001), escritor, ilustrador e pesquisador brasileiro, os vínculos entre a literatura infantil e os contos de tradição popular são muitos e evidenciam-se tanto no plano da enunciação/forma quanto no do conteúdo/temática. Abordaremos essa questão com mais propriedade no próximo tópico.

4 CANDIDO, Antonio. “O direito à literatura”, 2004, p. 175. 
promovendo um concurso de histórias, embarcam numa série de aventuras para ganhar o primeiro prêmio: uma bicicleta com as cores da bandeira nacional. Confrontadas, por um lado, com problemas "externos", relativos à precária situação socioeconômica do seu país, que, na altura dos eventos narrados na obra em questão, encontrava-se em meio a uma violenta guerra civil $^{5}$, e, por outro, com problemas “internos", de ordem mais psicológica e afetiva, as crianças imaginadas por Ondjaki conseguem dar conta da complexa atividade psíquica infantil, muitas vezes desconsiderada por outros autores.

É precisamente esse último aspecto que a nossa análise de $A$ bicicleta que tinha bigodes irá privilegiar, ao escolher como chave de leitura a construção psicológica de algumas das personagens principais: especialmente do narrador-protagonista e Isaura, a menina que "tem sempre ideias

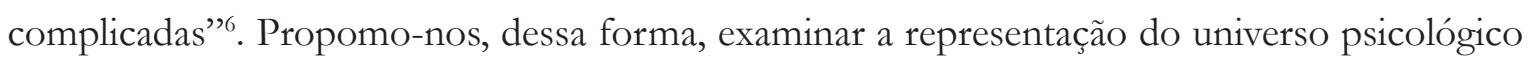
infantil no referido romance, em especial quando esse é confrontado com a psicologia adulta, para identificar o seu funcionamento singular e refletir sobre as possibilidades estéticas que o texto literário adquire quando incorpora traços subjetivos do seu leitor-alvo, a criança.

Para tanto, dividimos o trabalho em dois momentos relativamente autônomos, mas que, em verdade, convergem para atingir nosso objetivo principal. Assim, num primeiro momento, mais histórico-panorâmico, discutimos as origens da literatura infantil e cotejamos as mutações pelas quais o conceito de uma literatura "para crianças" sofreu ao longo do tempo, fundamentados, principalmente, nas teses de Ricardo Azevedo e Marisa Lajolo e Regina Zilberman. Em seguida, comentamos, muito brevemente, o contexto socio-histórico da Angola pós-independência e o início da produção literária para crianças nesse país, servindo-nos do apanhado realizado pela professora Maria C. Fernandes. No segundo momento, mais teórico-analítico, recorremos à teoria psicanalítica, sobretudo aos estudos do seu fundador, Sigmund Freud, e da psicanalista austríaca Melanie Klein, para compreender as idiossincrasias da dinâmica psíquica infantil. Também discutimos, nessa mesma seção, o trabalho de Bruno Bettelheim, figura pioneira no que se refere à crítica psicanalítica da literatura infantil. Finalmente, articulando as considerações elencadas até então, debruçamo-nos sobre $A$ bicicleta que tinha bigodes, com vistas a lançar luz sobre as vicissitudes da subjetividade infantil e os contornos mais representativos que essa ganha quando mimetizada no texto literário.

\section{Pensando a literatura infantil e seu lugar no contexto angolano}

Antes de enveredar pelas trilhas que a literatura infantil percorreu na história, é interessante delimitar a concepção de "literatura" e "infantil" que servirão de base para nossas discussões.

5 Pouco depois de sua independência, conquistada após quatorze anos de guerra contra Portugal, Angola naufragou num conflito interno entre os principais movimentos políticos que pretendiam governar o recém-liberto país, quais sejam: o Movimento Popular de Libertação de Angola (MPLA), de orientação socialista e financiado pela antiga União Soviética (URSS), e a União Nacional para a Independência Total de Angola (UNITA), de orientação liberal e financiada, em conjunto, pelos Estados Unidos e pela África do Sul (cf. BIRMINGHAM, Breve história da Angola moderna: séculos XIX-XXI, 2017).

6 ONDJAKI. A bicicleta que tinha bigodes, 2012, p. 14. 
Quanto ao primeiro conceito, fazemos nossas as palavras de Candido ${ }^{7}$ segundo quem, a grosso modo, a literatura diz respeito a "todas as criações de toque poético, ficcional ou dramático em todos os níveis de uma sociedade, em todos os tipos de cultura, desde o que chamamos folclore, lenda, chiste, até as formas mais complexas e difíceis da produção escrita das grandes civilizações". Aceitando essa definição e suas implicações, poderíamos argumentar que a literatura infantil nada mais é do que qualquer "criação de toque poético, ficcional ou dramático" direcionada especialmente para um público infantil ou jovem, em oposição, digamos, a uma literatura propriamente "adulta" ou "para adultos".

Entretanto, a questão que se coloca é muito mais complexa, pois os limites entre o mundo infantil e o mundo adulto nem sempre foram tão nítidos quanto o são na contemporaneidade. Aliás, em grande parte da história ocidental eles se misturavam, chegando, muitas vezes, a confundir-se por completo:

\footnotetext{
Participando da vida comunitária, dos costumes sociais, hábitos, linguagem, jogos, brincadeiras e festas, aparentemente não havia, no período medieval, assuntos que a criança não pudesse conhecer. Os temas da vida adulta, as alegrias, a luta pela sobrevivência, as preocupações, a sexualidade, a morte, a transgressão das regras sociais, o imaginário, as crenças, as comemorações, as indignações e perplexidades eram vivenciadas por toda a comunidade, independentemente de faixas etárias. $\mathrm{Na}$ verdade, a criança de mais de sete anos ocupava, ao que parece, o papel de um pequeno adulto, inexperiente e frágil, incapaz de certas coisas talvez, mas já uma pessoa na vida, importante como força na família e na sociedade ${ }^{8}$.
}

Durante a Idade Média, a criança não era percebida como um sujeito biologicamente frágil e psicologicamente imaturo, que demandasse cuidados especiais de qualquer tipo, mas, antes disso, era quase um "pequeno adulto". Consequentemente, crianças e adultos transitavam pelos mesmos espaços sociais e partilhavam as mesmas responsabilidades. Era bastante comum, por exemplo, que pais e filhos trabalhassem juntos para garantir o seu sustento, uma vez que a educação formal era um privilégio reservado aos nobres e abastados. Aquilo que hoje entendemos por "infância" começou a tomar forma apenas na modernidade, nomeadamente entre o final do século XVII e início do século XVIII ${ }^{9}$, como parte vital do projeto sociopolítico que a burguesia desejava implementar.

O século XVIII foi, entre outras coisas, um período de grande convulsão política e transformação social. Por um lado, no plano da filosofia e das ciências, o Iluminismo instalou

7 CANDIDO, Antonio. “O direito à literatura”, 2004, p. 169-191.

8 AZEVEDO, Ricardo. "Literatura infantil: origens, visões da infância e certos traços populares". Publicado in: Presença Pedagógica, Belo Horizonte, Editora Dimensão, n. 27, mai./jun. 1999 e em Cadernos do Aplicaşão, v. 14, n. 1/2, Universidade Federal do Rio Grande do Sul, jan./fev. 2001.

9 Daí a insistência de alguns estudiosos da área em circunscrever, um tanto rigidamente, as origens da literatura infantil nesse momento histórico, desconsiderando as afinidades desse gênero com as narrativas de tradição popular que prosperaram durante todo o medievo, como causos, fábulas, cantigas etc. (Ibidem, s/p.). 
o imperativo da lógica e da razão, condenando toda forma de pensamento que não estivesse firmemente assentada na realidade material. Por outro lado, no plano político e socioeconômico, a Revolução Francesa (1789-1799) abalou seriamente o status da monarquia como único paradigma de organização política válido, ao apontar para outras possibilidades de governo mais democráticas, enquanto a Revolução Industrial (1760-1840) alterou substancialmente as condições de produção econômica e de divisão social do trabalho, substituindo o modelo artesanal pelo modelo salarial. Esses eventos reformularam o tecido social do Ocidente, primeiro na Europa e depois no resto do globo, ao encetarem o declínio dos sistemas que organizavam o mundo medieval (como o feudalismo e as monarquias absolutistas) e o despontar das instituições que inauguram a era moderna (como o capitalismo e os Estados-nação).

Se na Idade Média a classe social dominante, única detentora do poder político e econômico, foi a aristocracia, testemunhamos, na modernidade, a consolidação da burguesia e do seu estilo de vida singular. Para firmar sua hegemonia ideológica, fomentou duas instituições em particular: a família e a escola. É verdade que ambas instituições já existiam, mas elas passaram por uma profunda transformação para veicular a visão de mundo burguesa e seus respectivos valores. Assim, a família, que em tempos passados era muito extensa e munida de um forte sentimento de comunidade, visto que participava amplamente da vida pública, viu seu tamanho gradualmente reduzido e seu envolvimento público cada vez menos incentivado. Adquiriu, a partir de então, uma configuração mais doméstica, privada e sua principal função passou a ser o cuidado e a formação moral da criança, que, por sua vez, herdou os atributos de fragilidade e dependência que a caracterizam até os dias que correm:

\begin{abstract}
A manutenção de um estereótipo familiar, que se estabiliza através da divisão do trabalho entre seus membros (ao pai, cabendo a sustentação econômica, e à mãe, a gerência da vida doméstica privada), converte-se na finalidade existencial do indivíduo. Contudo, para legitimá-la ainda foi necessário promover, em primeiro lugar, o beneficiário maior desse esforço conjunto: a criança. A preservação da infância impõe-se enquanto valor e meta de vida; porém, como sua efetivação somente pode se dar no espaço restrito, mas eficiente, da família, esta canaliza um prestígio social até então inusitado ${ }^{10}$.
\end{abstract}

Foi assim que se estabeleceu a nossa noção da infância como um período de cândida inocência, de maturação e preparo para as turbulências da vida adulta, amparando-se, sobretudo, nos discursos da pediatria, da psicologia e da pedagogia. De fato, essa última disciplina cumpriu um papel central na naturalização dessa nova maneira de se pensar a condição da criança, ao colocar a escola - a segunda das instituições burguesas que mencionamos há pouco - no centro das suas discussões. Lajolo e Zilberman elencam as mudanças mais determinantes pelas quais o espaço escolar passou nessa altura para atender às novas exigências que a burguesia lhe fez:

10 LAJOLO, Marisa; ZILBERMAN, Regina. Literatura infantil brasileira: história \& histórias, 2007, p. 16. 
Tendo sido facultativa, e mesmo dispensável até o século XVIII, a escolarização converte-se aos poucos na atividade compulsória das crianças, bem como a freqüência às salas de aula, seu destino natural. Essa obrigatoriedade se justificava com uma lógica digna de nota: postulados a fragilidade e o despreparo dos pequenos, urgia equipá-los para o enfrentamento maduro do mundo. Como a família, a escola se qualifica como espaço de mediação entre a criança e a sociedade, o que mostra a complementaridade entre essas instituições e a neutralização do conflito possível entre elas ${ }^{11}$.

Uma vez que a imagem da criança como um ser "frágil" e "desamparado" se fixa no imaginário popular, ela torna-se o elo que ao mesmo tempo concilia e consagra a família e a escola. Adquirem, assim, grande relevância social, na medida em que seria nesses espaços que a formação moral, civil e intelectual de crianças e jovens, imprescindível para a continuação do modelo burguês de sociedade, se concretizaria. É nesse contexto que a literatura infantil faz sua estreia, servindo, nesses primeiros momentos, como uma das principais ferramentas pedagógicas para a transmissão da cosmovisão hegemônica ${ }^{12}$. Tendo o seu público-alvo estabelecido e seu objetivo traçado, a literatura para crianças pôde prosperar. Os primeiros títulos vieram a público no final do século XVII, tornando-se cada vez mais comuns, até que, em meados do século XVIII, com os avanços tecnológicos na área da tipografia e o paulatino aumento nos níveis de alfabetização entre a população infantil, já constituíam uma miríade de textos bastante diversa.

Fazem parte desse momento inaugural obras célebres como as Fábulas (1668-1694), de La Fontaine, os Contos da Mamãe Gansa (1697), de Charles Perrault, e os Contos dos Grimm (18121814), compilados pelos irmãos Jacob e Wilhelm Grimm. Nesses textos, evidencia-se muito claramente uma "função utilitário-pedagógica", que limita o livro infantil a uma espécie de canal a partir do qual "os valores sociais passam a ser veiculados, de modo a criar para a mente da criança hábitos associativos que aproximam as situações imaginárias vividas na ficção a conceitos, comportamentos e crenças desejados na vida prática, com base na verossimilhança que os vincula"13. Essa áurea doutrinária marcará negativamente o estatuto literário do gênero, que, ainda hoje, tem sua qualidade estética contestada por aqueles que a rotulam de mero didatismo.

No entanto, a literatura infantil continuou evoluindo e se redefinindo incessantemente, até alcançar outros horizontes que não apenas o pedagógico e conquistar o reconhecimento do qual atualmente começa a gozar. Acompanhando as transformações sociais, políticas e econômicas do mundo material em que, como produto cultural, está inevitavelmente inserida, incorporou na sua estrutura interna as principais questões que afligem a sensibilidade moderna. Assistimos, assim, desde o final do século XIX e durante todo o século XX, à produção de um

11 Ibidem, p. 16.

12 PALO, Maria José; OLIVEIRA, Maria Rosa D. Literatura infantil: voz de criança, 2006.

13 Ibidem, p. 8. 
corpo de textos que conseguiram transcender a prerrogativa educacional que por tanto tempo a definiu para fundar uma tradição literária com contornos próprios:

\begin{abstract}
Apesar de ser um instrumento usual de formação da criança, participando, nesse caso, do mesmo paradigma pragmático que rege a atuação da família e da escola, a literatura infantil equilibra - e, freqüentemente, até supera essa inclinação pela incorporação ao texto do universo afetivo e emocional da criança. Por intermédio desse recurso, traduz para o leitor a realidade dele, mesmo a mais íntima, fazendo uso de uma simbologia que, se exige, para efeitos de análise, a atitude decifradora do intérprete, é assimilada pela sensibilidade da criança ${ }^{14}$.
\end{abstract}

Com efeito, o perfil da literatura infantil contemporânea vai de encontro com o seu passado doutrinador, tendo em vista que a sua dimensão estética se sobrepôs à sua dimensão pragmática. Como Lajolo e Zilberman bem colocaram, isso não significa dizer que a literatura para crianças tenha perdido por completo o seu potencial pedagógico, formador, até mesmo porque a escola continua sendo o espaço em que ela mais circula. O que podemos afirmar é que ela alargou seus domínios para atender melhor às expectativas do seu público. Isso se deu, em parte, graças a algumas mudanças na nossa maneira de enxergar a criança, que passou de ser vista como um ser incompleto, lacunar, enfim, incapaz, que precisaria ser moldado para encarar o mundo "real", para tornar-se "um ser em formação, cujo potencial deve se desenvolver em liberdade, mas orientado no sentido de alcançar total plenitude em sua realização"

Guardadas as devidas proporções, o itinerário que acabamos de muito sucintamente descrever foi o mesmo em diversas partes do globo. No entanto, faz-se necessário comentar algumas particularidades do caso angolano para entendermos melhor o contexto de produção/ recepção do nosso objeto de estudo, A bicicleta que tinha bigodes. A África do século XX, especialmente na segunda metade, serviu de palco para uma série de conflitos bélicos entre as potências europeias (Inglaterra, França e Portugal) e suas colônias. Essas últimas exigiam sua independência política e o reconhecimento internacional da sua soberania administrativa. Não surpreende, portanto, que durante os anos de guerra colonial a produção literária tenha se reduzido consideravelmente, e que os poucos títulos que de fato puderam ser publicados tratassem, na sua grande maioria, de questões marcadamente ideológicas, relacionadas à construção da imagem nacional de Angola e da guerra contra as forças colonizadoras.

Esse quadro só começou a modificar-se com o fim da guerra colonial e a subsequente proclamação de independência por parte de Angola, a 11 de novembro de 1975. Uma vez que a instabilidade política e o caos social engendrados pelo conflito bélico diminuíram, a sociedade angolana viu florescer uma profícua cultura literária. O incentivo financeiro e o suporte editorial/logístico de algumas instituições foram imprescindíveis nesse momento de

14 LAJOLO, Marisa; ZILBERMAN, Regina. Literatura infantil brasileira: história \& histórias, 2007, p. 19.

15 COELHO, Nelly Novaes. Literatura infantil: teoria, análise, didática, 2000, p. 27. 
reestruturação das letras nacionais, principalmente aquele oferecido pela União dos Escritores Angolanos (UEA), fundada poucas semanas depois da independência, em 10 de dezembro de 1975. Além de servir como um importante lugar de encontro e discussão para escritores, jornalistas e intelectuais de diversas áreas interessados em literatura, a instituição fundou a primeira casa editorial de grande circulação do país, publicando a obra de autores que hoje reconhecemos como canônicos (Luandino Vieira, Pepetela, Manuel Rui e outros). Sobre o impacto social que isso causou, Fernandes coloca:

\begin{abstract}
Aqueles que escreviam e guardavam seus textos em gavetas, os que queimaram o tempo preenchendo folhas de cadernos durante o cativeiro nas masmorras coloniais e no exílio, ou nas zonas de guerrilha libertadas saíram do anonimato. A UEA foi, de facto, a primeira editora angolana, tendo publicado no início obras de grande valor literário e em grandes tiragens. Do lado das pessoas, houve grande entusiasmo, havia a ânsia de conhecer a literatura angolana escrita pelos próprios angolanos, e mesmo os que não sabiam ler adquiriam livros, talvez com a esperança de em pouco tempo poderem lê-los, visto que a tarefa de alfabetização conheceu grande dinamismo e adesão populacional durante o regime socialista que vigorou nos primeiros anos de independência ${ }^{16}$.
\end{abstract}

É nesse período que as primeiras discussões sistemáticas sobre a problemática da literatura infantil tiveram lugar em Angola. Antes disso, a literatura que circulava entre o público infantil e juvenil era predominantemente de caráter oral, isto é, narrativas tradicionais que eram passadas de uma geração para outra como parte integral da formação cultural do jovem. Segundo Fernandes ${ }^{17}$, escritores preocupados em produzir literatura para crianças debatiam entre si sobre as particularidades que esse gênero deveria vir a ter, passando tanto por aspectos formais (Qual a língua a ser utilizada? A língua portuguesa ou as línguas nativas?) quanto aspectos temáticos (Adaptar os contos tradicionais? Escrever novas histórias?). Nesse ínterim, vieram a lume as primeiras obras dedicadas especialmente para um público infantil, quais sejam: $A s$ aventuras de Ngunga (1975), de Pepetela, A caixa (1977), de Manuel Rui e A montanha do sol (1989), de Maria Eugénia Neto.

Nesses textos, "profundamente engajados política e ideologicamente à causa nacional"18, podemos notar um esforço por tratar assuntos um tanto espinhosos - porém de grande relevância, especialmente se levarmos em consideração que Angola estava recuperando-se de uma guerra devastadora - como a violência, a morte e o nacionalismo. Para Fernandes ${ }^{19}$, é claro que essas narrativas "visavam formar e informar as futuras gerações para as questões do presente e a perspectiva do futuro, mentalizando-as que só através de estudo e da participação nas tarefas

16 FERNANDES, Maria Celestina. "Surgimento e desenvolvimento da literatura infantil angolana pósindependência".

17 Ibidem.

18 Ibidem.

19 Ibidem. 
da revolução, a situação de opressão e de obscurantismo poderia ser revertida". Entendemos, assim, que essa primeira "fase" da literatura infantil angolana tomou para si a missão de reparar o espírito comunitário e reforçar a fé na jovem nação, ao ofertar para seus leitores mirins ferramentas subjetivas que lhes permitissem, ainda que minimamente, compreender melhor a realidade e enfrentá-la com dignidade.

A partir das décadas de 1980 e 1990, a literatura infantil angolana ganhou outras camadas de significação que apuraram seu escopo formal e temático, o que, por sua vez, lhe permitiu transitar por novos espaços e conquistar ainda mais leitores. Fernandes ${ }^{20}$ aponta como marcos ilustrativos dessas evoluções o surgimento do programa radiofônico Rádio-Pio, no qual eram lidas estórias e poesia infantis, além de contos e cantigas tradicionais, e o Suplemento Infantil, seção do Jornal de Angola que publicava textos curtos direcionados ao público infantil. Despontam, também, escritores que se dedicaram assiduamente à consolidação de uma tradição de literatura para crianças no seu país, entre eles: Dário de Melo, Octaviano Correia, Gabriela Antunes, Rosalina Pombal e o próprio Ondjaki, autor da obra estudo da nossa pesquisa. Por ser um autor jovem, nascido em 1977 - dois anos depois da Independência de Angola (que se deu a 11 de novembro de 1975) -, Ondjaki vivenciou a infância em meio à guerra civil angolana, marcada pela disputa de poder entre o partido da situação, situado no sul moçambicano, O Movimento Popular pela Libertação de Angola (MPLA) e a oposição, União Total pela Independência de Angola (UNITA). Foi um período de muita expectativa frustrada, já que a condição de vida dos angolanos não teve uma melhora considerável após a queda do domínio português. Segundo Kabengele Munanga (1993), houve uma mera transferência de poder, passado do governo português à elite africana, que herdou o modus operandi do colonizador, bem como seus vícios. Ainda segundo o autor: "As elites africanas se comportam como se fossem já convencidas de sua incapacidade e da de seus povos em inventar um modelo adaptado ao meio, a sua realidade econômica, a suas tradições e a seus valores culturais" ${ }^{21}$. Este momento sóciohistórico concernente às primeiras décadas pós-Independência é retratado no objeto de nossa pesquisa a partir das demonstrações de descaso com a população e má gestão do governo, exemplificado a partir do relato das relações de poder entre militares e civis, do ambiente de pobreza no qual vivia a maioria da população e das constantes faltas de luz ocorridas e tratadas de forma irrelevante pelas autoridades. Em outra obra do mesmo autor, Os transparentes (2013), existe a crítica acerca da falta de água contínua nos bairros periféricos e da corrupção dos governantes. Consideremos, pois, que o autor se posiciona criticamente, reiterando aspectos sociopolíticos relacionados à sua vivência como sujeito histórico.

\section{Configurações da psicologia infantil em $A$ bicicleta que tinha bigodes, de Ondjaki}

O arcabouço teórico da psicanálise foi construído sobre os fundamentos conceituais da medicina, psiquiatria e psicologia europeias do final do século XIX, herdeiras da utopia

20 Ibidem.

21 MUNANGA, “África - Trinta anos de processo de independência”. Revista USP, 1993, p. 105. 
iluminista, que enxergava na razão o apanágio de todos os males do homem, e atravessadas pela concepção positivista de fazer ciência, que reconhecia como válido apenas o conhecimento produzido pelo método científico. No entanto, Sigmund Freud (1856-1939), seu fundador, nunca limitou seu trabalho intelectual às prerrogativas epistemológicas que vigoravam no seu tempo, levando sua disciplina para horizontes nunca antes explorados.

Uma das posições mais inovadoras e, por isso mesmo, mais polêmicas da psicanálise foi a sua concepção de criança. Diferentemente da pedagogia oitocentista, por exemplo, que entendia a criança como um ser neutro, amorfo, que precisaria ser moldado para adequar-se às convenções do mundo dito "civilizado", ou seja, dos adultos, a psicanálise freudiana a entendia como um ser desejante, individual e, sobretudo, atemporal, no sentido de que as vicissitudes da psique infantil continuariam vivas na psique adulta, determinando - sempre inconscientemente - seu destino. Através de textos seminais como os Três ensaios sobre a teoria da sexualidade (2016 [1905]) e Análise da fobia de um garoto de cinco anos (2015 [1908]), mais conhecido como o "caso Hans", Freud subverte quase todas as convenções que, à época, circulavam sobre o período da infância, especialmente aquelas que a desenhavam como uma fase idílica, sublime e livre de angústias de qualquer tipo:

\begin{abstract}
Portanto, a descoberta da importância da infância decorre da existência não só de uma sexualidade infantil, mas de um sujeito sexualmente desejante na infância. Assim, a psicanálise passa a se conectar com a história do sujeito, de um ser que desde muito cedo escreve suas páginas com seus desejos, proibidos e realizados, admitidos e recalcados. A infância recebe em seus braços tudo aquilo de que se lhe considerava ainda imune, acrescido do problema de que estas vivências são compreendidas como formadoras, constituintes. Isto obviamente faz da infância objeto de atenções teóricas e preocupações pedagógicas 22 .
\end{abstract}

É inegável que durante toda a sua produção intelectual, em alguns momentos mais explicitamente do que em outros, Freud teorizou sobre o estatuto subjetivo da criança, na medida em que era na infância que ele situava a gênese da sintomatologia neurótica que afetava seus pacientes. Efetivamente, como nos informa Diana L. Corso, "sua crença na precocidade das fantasias e da constituição do sujeito faz com que tenhamos desde o começo uma subjetividade com que dialogar, mais do que uma criança a formar" ${ }^{23}$. Isto posto, nas primeiras décadas da psicanálise, foram poucos aqueles que se aventuraram com profundidade pelos meandros da mente infantil, desde sempre tão incompreendida.

Melanie Klein (1882-1960), psicanalista austríaca, foi uma das que enveredou por esse caminho. Bebendo na fonte freudiana e expandindo conceitos formulados pelo mestre vienense, produziu, durante pouco mais de trinta anos, uma vasta obra, que, na sua radical originalidade,

22 CORSO, Diana Lichtenstein; CORSO, Mário. Fadas no divã: psicanálise nas histórias infantis. Porto Alegre: Artmed, 2006, p. 105.

23 CORSO, Diana Lichtenstein; CORSO, Mário. Fadas no divã: psicanálise nas histórias infantis, 2006, p. 109. 
revolucionou a clínica para crianças. Ainda que tenha se colocado repetidas vezes ao longo da sua vida como uma continuadora da psicanálise clássica, o ulterior desenvolvimento do seu pensamento acarretou algumas divergências dessa. Assim, se para Freud o início da vida psíquica era regido pelo autoerotismo ${ }^{24}$, o que equivale a dizer que o infante, pelo menos nesse momento inicial, não se relaciona com objetos externos, mas apenas com ele mesmo, e o complexo de Édipo ${ }^{25}$ só eclodiria por volta dos três a cinco anos de idade, para Klein já existem relações objetais desde os primórdios da nossa existência, o que, por sua vez, possibilita Klein a recuar consideravelmente a gênese do complexo de Édipo, situando-a por volta dos três meses de vida. Outra tese que é de suma importância na compreensão kleiniana do sujeito infantil é a constatação de que é "a vida fantasística que modela a realidade, e não o contrário" 26 . No eterno debate sobre os imbricamentos entre a realidade e a fantasia, Klein chama atenção para a influência da segunda, ao afirmar que são as fantasias inconscientes que nos permitem, concomitantemente, aceder e dar forma ao mundo material.

Como pudemos observar, a infância é uma temática bastante cara à psicanálise, que lança mão do seu aparato teórico para explorar os recantos mais obscuros da alma humana. Daí, por exemplo, o seu interesse na arte e, mais especificamente, na literatura, uma vez que esses campos se prestam muito bem para a decifração de enigmas que atormentam o homem desde a aurora da civilização. Apesar da literatura "sem adjetivos", ou seja, a literatura "adulta" ter sido amplamente estudada na história da psicanálise, ao ponto, inclusive, da crítica psicanalítica ser reconhecida mundialmente como uma das abordagens mais populares do texto literário, a literatura infantil não foi, por muito tempo, alvo de maiores discussões. Desconsiderando alguns casos isolados, foi apenas no ano de 1976 que uma obra integralmente dedicada ao estudo da literatura para crianças veio a lume, de autoria de Bruno Bettelheim, psicanalista austríaco radicalizado nos Estados Unidos.

Bettelheim defendia que a convivência com a literatura infantil era indispensável para o desenvolvimento saudável das crianças, na medida em que o contato com a obra de arte e, nesse caso em particular, a obra de ficção, promoveria amadurecimento emocional de grande valia. Entretanto, ele frisa que para alcançar essas benesses a literatura apresentada ao infante deve cumprir algumas prerrogativas, que vão desde a qualidade do texto até sua adequação para a faixa etária e capacidade cognitiva/afetiva do leitor pretendido:

Para que uma estória realmente prenda a atenção da criança, deve entretê-la e despertar sua curiosidade. Mas para enriquecer sua vida, deve estimular-lhe a

\footnotetext{
24 Segundo Roudinesco e Plon (1998, p. 531), o "autoerotismo”, também conhecido como "narcisismo primário", "diria respeito à criança e à escolha que ela faz de sua pessoa como objeto de amor, numa etapa precedente à plena capacidade de se voltar para objetos externos".

25 Ainda segundo Roudinesco e Plon (1998, p. 166), o complexo de Édipo "é a representação inconsciente pela qual se exprime o desejo sexual ou amoroso da criança pelo genitor do sexo oposto e sua hostilidade para com o genitor do mesmo sexo". Trata-se de um conceito-chave para a teoria psicanalítica, que vê na passagem pelo complexo de Édipo a entrada do sujeito no mundo da linguagem, da cultura.
}

26 COSTA, Terezinha. Psicanálise com crianças, 2010, p. 30. 
imaginação: ajudá-la a desenvolver seu intelecto e a tornar claras suas emoções; estar harmonizada com suas ansiedades e aspirações; reconhecer plenamente suas dificuldades e, ao mesmo tempo, sugerir soluções para os problemas que a perturbam. Resumindo, deve de uma só vez relacionar-se com todos os aspectos de sua personalidade - e isso sem nunca menosprezar a criança, buscando dar inteiro crédito a seus predicamentos e, simultaneamente, promovendo a confiança nela mesma e no seu futuro27.

Nessa perspectiva, a literatura infantil pode atuar duplamente. Para nós, adultos, serve de ensejo para compreender melhor a dinâmica própria à psicologia da criança, e, para esta, serve de "mola propulsora" para a estruturação e amadurecimento do seu universo interno.

Adentrando no universo narrativo da obra em questão, deparamo-nos com um grupo de crianças: o narrador-protagonista, que não é nomeado, Isaura e JorgeTemCalma, que vivem em um dos musseques de Luanda (bairros periféricos, habitados na sua grande maioria pela população de baixa renda). Já na escolha do locus narrativo é possível a crítica social feita pelo narrador. Conforme assinalamos na introdução, o conflito dramático que mobiliza a diegese se dá quando o narrador-protagonista fica sabendo de um concurso de estórias promovido pela Rádio Nacional de Angola, cujo primeiro prêmio era uma bicicleta com as cores da bandeira nacional (amarelo, vermelho e preto). Interessado em ganhar o referido prêmio, convoca seus amigos para que o ajudem a escrever uma história. No entanto, nem Isaura nem JorgeTemCalma conseguem pensar em uma boa trama. Embarcam, então, numa série de (des)aventuras para encontrar alguém que de fato os pudesse auxiliar.

Uma das primeiras figuras em quem o narrador-protagonista pensa é o tio Rui, "aquele que escreve bué28 de poemas" ${ }^{29}$. O personagem é uma referência e homenagem ao escritor angolano Manuel Rui (1941-), um dos nomes mais importantes da literatura angolana moderna, e cujas obras marcaram positivamente a infância de muitos angolanos. Aliás, no prefácio de A bicicleta que tinha bigodes, Ondjaki confessa sua admiração pelo referido autor e lhe dedica a obra. Voltando ao universo estritamente intradiegético, já nas primeiras linhas o narradorprotagonista apresenta o tio Rui como alguém que "inventa estórias e poemas que até chegam a outros países muito internacionais" ${ }^{30}$, donde sua disposição a solicitar seu conselho. O fato de o narrador possuir uma relação tão próxima com o tio Rui, cuja produção literária é tão reconhecida internacionalmente e por quem nutre uma grande estima, ganha alguns sentidos adicionais quando levamos em consideração o contexto imediato do nosso corpus. Assim, poderíamos pensar que a personagem do escritor renomado indica a importância que figuras inspiradoras podem chegar a ter na vida psicológica e no desenvolvimento afetivo das crianças,

27 BETTELHEIM, Bruno. A psicanálise dos contos de fadas, 2002, p. 5.

28 Como a narrativa é em primeira pessoa, o texto é repleto de marcadores discursivos da oralidade. A variante informal do português angolano é extensivamente utilizada, como neste caso específico. "Bué" significa, segundo o glossário disponibilizado ao final do livro, "grande número ou quantidade".

29 ONDJAKI. A bicicleta que tinha bigodes, 2012, p. 11.

30 Ibidem, p. 9. 
especialmente em momentos de crise política e social. A ideia de recorrer ao tio veio à mente do narrador-protagonista enquanto se preparava para dormir. Já deitado, ele reflete:

De noite, a falar com minha almofada, eu até já prometi bem as coisas: "se
eu ganhar a bicicleta colorida, vou deixar todos da minha rua andarem sem
pedir nada em troca, nem gelados nem xuínga". Essa promessa assim bem
dura de fazer é que me fazia acreditar que eu ia mesmo ganhar a bicicleta31.

Neste excerto, podemos identificar alguns movimentos discursivos que remetem à psicologia infantil. $\mathrm{O}$ primeiro deles é o fato de o personagem se dirigir a sua almofada, colocando um objeto inanimado na posição do seu interlocutor. Segundo a compreensão psicanalítica, em particular a de orientação kleiniana, as crianças têm uma tendência muito forte de emprestar qualidades humanas a seres que normalmente não as apresentariam (objetos, animais etc.). Isso se dá porque os principais mecanismos que regem a sua psique são a projeção e a introjeção, através dos quais recobre tanto o mundo material quanto o mundo interno de significado. Inclusive, a literatura (infantil e "adulta" da mesma forma) tem historicamente se apropriado, com muito sucesso, dessa inclinação humana pela "personificação".

O segundo movimento discursivo diz respeito àquilo que Klein (1997 [1952]) chamou de "onipotência infantil". Trata-se de um traço característico do modo de pensar infantil, que tem no enlaçamento entre realidade física e realidade psicológica o seu fundamento. Essa dinâmica fica evidente quando o narrador-protagonista demonstra acreditar que, pelo simples fato de ter "feito uma promessa assim bem dura de fazer", teria o seu desejo de ganhar a bicicleta atendido. Duas ideias subjazem essa forma de pensar, nomeadamente: 1) a crença no poder da palavra e do pensamento, haja vista que o ato de verbalizar uma vontade seria o suficiente para torná-la realidade e 2) a crença na força do "bem", uma vez que o personagem entende que sua disposição em dividir a bicicleta com seus amigos "sem pedir nada em troca" aumentariam suas chances de ter sua vontade feita.

No dia seguinte, o protagonista-narrador procura o tio Rui para lhe pedir uma estória nova, que ele pudesse inscrever no concurso para ganhar a tão sonhada bicicleta. Todavia, o tio Rui lhe explica que não poderia fazer isso, uma vez que seria injusto para com as outras crianças do concurso que não conhecessem um escritor, e incentiva o personagem a pensar, ele mesmo, numa boa história. Ainda que um tanto desapontado com a situação, o narrador-protagonista continua determinado a ganhar seu prêmio. É neste momento da narrativa que ele faz menção aos seus dois amigos, começando com a Isaura:

\footnotetext{
A Isaura tem sempre ideias complicadas. Fica muito tempo sentada no quintal dela a olhar as andorinhas, as lesmas e até conhece cada gafanhoto do jardim dela. Dá nomes de pessoas aos bichos mas não sabe bem a tabuada.
}

31 Ibidem, p. 10. Segundo o glossário ao qual fizemos menção na nota no 28, "xuínga" significa "chiclete". 
- Quatro vezes quatro? - perguntava o CamaradaMudo quando ainda dava explicações de matemática.

- Não sei, mas por exemplo, o gafanhoto SamoraMachel gosta mais das plantas da casa do tio Rui, e só come antes das onze. Se está muito sol, vai-se esconder.

Nós riamos daquela maluquice dela, ainda perguntávamos mais.

- Seis vezes três?

- Não sei, mas a lesma Senghor é muito estranha porque anda a fazer uma casa com pedrinhas que vai buscar no fundo do quintal e um dia destes pode ser pisada ${ }^{32}$.

Aqui se repetem os mesmos mecanismos discursivos que acabamos de identificar no narrador-protagonista, isto é, a personificação do mundo material como consequência de processos intermitentes de projeção/introjeção. Contudo, eles parecem ser bem mais presentes na construção subjetiva de Isaura do que na do seu amigo. Isso é marcado textualmente já na primeira caracterização de Isaura como aquela que "tem sempre ideias complicadas". A menina, que demonstra possuir uma imaginação bastante fértil e uma curiosidade intelectual aguçada, passa muito tempo observando os animais que a cercam. Interessante notarmos a gradação que se produz quando o narrador-protagonista elenca alguns desses animais que Isaura admirava com tanto zelo. Primeiro aparecem as andorinhas (que remetem ao céu, ao alto, e que, pelo menos em relação com os outros dois animais, são grandes), seguidas das lesmas (que remetem ao solo, ao baixo, ou seja, houve um movimento de cima para baixo, e que são menores do que as andorinhas) até chegar nos gafanhotos (que remetem ao plano subterrâneo, além de serem, entre os três animais citados, os de menor tamanho).

De resto, o que há de mais notável em Isaura é a sua insistência em atribuir características e faculdades humanas aos bichos que encontra, chegando a confeccionar verdadeiras personalidades para eles. Levando em consideração uma série de qualidades e defeitos que ela mesmo confere aos animais que "adota", escolhe nomes de figuras emblemáticas da história para batizá-los. O seu gato, por exemplo, era bastante arisco, e, por isso mesmo, chamava-lhe de Tátecher, em referência à Primeira-Ministra do Reino Unido durante a década de 1980, Margaret Thatcher, popularmente conhecida como a Iron Lady, ou "Dama de Ferro". Esse mesmo gato, depois de ser castrado e tornar-se mais manso, foi rebatizado por Isaura de Ghandi, em referência ao herói da independência da Índia e símbolo do movimento antiviolência.

Um outro episódio no qual é bem demarcada essa propensão de Isaura para projetar-se no mundo que a cerca pode nos servir para compreender melhor a lógica da psicologia infantil, pelo menos nos termos em que a estamos pensando até aqui. Como havíamos mencionado no tópico anterior, A bicicleta que tinha bigodes (2013) tem como espaço as periferias de Luanda num período de instabilidade social, política e econômica, em razão da guerra civil que Angola estava enfrentando. Isto posto, a falta de água e problemas com a energia elétrica eram muito comuns, e a narrativa de Ondjaki não se furta dessa realidade, ficcionalizando-a com rigor histórico.

32 Ibidem, p. 14-15. 
Assim, no universo intradiegético apagões eram recorrentes. Durante um deles, os protagonistas estavam brincando na rua quando ouviram um barulho e decidiram investigar sua causa. Ao chegarem à cena, perceberam que o Nove, motorista particular do GeneralDorminhoco, agente do exército que morava por perto, tinha atropelado Raúl, um dos sapos de Isaura. A menina ficou desolada e começou a chorar. Reclamou com o Nove, que não entendia ao todo o que tinha se passado. Em seguida, o GeneralDorminhoco se aproxima e conversa com as crianças. O interessante é o contraste que se dá entre a maneira pela qual a figura adulta - neste caso, o general - e a figura infantil - neste caso, Isaura - lidam com o ocorrido:

- Então tu dizes que o Nove atropelou um sapo?

- Sim, camarada General.

$-\mathrm{E}$ tu conhecias esse sapo?

- Esse sapo era meu.

- Era "teu”?

- Sim, vivia no meu quintal há muito tempo.

O GeneralDorminhoco riu, parecia que estava a gozar connosco. Depois acendeu uma lanterna e focou na mancha escura no chão.

- E como é que sabes que isto aqui era um sapo? Pode ser uma fruta podre, ou outro bicho qualquer.

- Mas eu sei que é o Raúl.

- Não sabes nada. E acabou a conversa porque a rua está muito escura e vocês nem deviam estar aqui a brincar. Já para casa todo mundo ${ }^{33}$.

Evidencia-se, em primeiro lugar, a perspectiva crítica às relações de poder entre o general do exército e a pequena Isaura, que é completamente desconsiderada pelo primeiro. Nessa perspectiva mais política, temos, por um lado, o GeneralDorminhoco, que representa a instituição militar, símbolo da repressão e da violência que o Estado utiliza para manter-se hegemônico, além de pertencer a uma classe social mais abastada (vide, por exemplo, ele possuir um carro e um motorista particular), e, de outro, temos Isaura, que é apenas uma criança e que pertence a uma classe social desfavorecida. Mas esse movimento de demérito do general para com Isaura não se limita à dimensão política, vai, isso sim, muito além dela. Na verdade, o que se configura nesse quadro é o embate entre duas maneiras de ver, de pensar e de entender o mundo, nomeadamente a do adulto e a da criança.

Nessa outra perspectiva, mais psicológica, o embate entre as personagens ganha outros significados, que se alinham àquilo que viemos discutindo ao longo do nosso trabalho. $\mathrm{O}$ GeneralDorminhoco não reconhece valor algum no sentimento que Isaura tinha pelo sapo Raúl, para ele era apenas um capricho infantil que não merecia muita atenção. No entanto, ao estudar as particularidades da mente infantil, entendemos que desde o ponto de vista de Isaura se tratava de um objeto que ela tinha investido afetivamente, ao ponto de lhe emprestar uma personalidade, um nome, enfim, de misturar-se psicologicamente com o sapo, que deixa de ser um mero animal para tornar-se, em última instância, uma parte dela mesma. Daí a magnitude

33 Ibidem, p. 22. 
que o evento teve para ela, que, ainda por cima, precisou lidar com a agressividade do general. Efetivamente, se o mundo interior da criança é marcado pela fantasia, pela força criadora da imaginação, o do adulto, não raro, é organizado pela razão, pelo ímpeto retificador da lógica. Não estamos, com isso, a sugerir que uma forma em particular seja inerentemente melhor do que a outra. Ambas fazem parte do desenvolvimento natural do homem, e, conforme os ensinamentos de Freud, no adulto elas coexistem.

\section{Considerações finais}

Ao longo do trabalho, pudemos conhecer parte da extensa jornada que a literatura infantil percorreu até alcançar a sua forma atual. Desde suas origens estritamente pedagógicas, até a conquista do estatuto literário, esse gênero precisou enfrentar uma série de obstáculos, tanto na sociedade leiga quanto nos círculos acadêmicos. Além disso, constatamos que a literatura infantil não diz respeito apenas às crianças, sendo igualmente importante para leitores adultos, especialmente para aqueles que, de uma forma ou de outra, convivem com crianças ou, ainda mais, se envolvem diretamente com a formação delas.

Essas considerações nos levaram a enveredar pelos meandros da psicanálise, que se mostrou uma disciplina bastante útil para pensar questões referentes às psicologias "adulta" e "infantil”. Através dos ensinamentos de Freud e Klein, esboçamos uma concepção de criança um tanto quanto diferente, na medida em que subverte muitas narrativas tidas como verdadeiras no senso comum. Munidos desse conhecimento, procuramos examinar como o texto literário representava a complexa realidade psíquica do infante. Para tanto, realizamos uma leitura analítica de $A$ bicicleta que tinha bigodes, do autor angolano Ondjaki, cuja perspectiva sócio-histórica não foi obliterada da narrativa.

Nesse movimento hermenêutico, constatamos que o escritor angolano conseguiu mimetizar as particularidades do universo infantil com êxito, haja vista que suas personagenscrianças encenam as alegrias e as angústias que caracterizam o período da infância de maneira bastante profunda. Com efeito, as (des)aventuras que o narrador-protagonista e Isaura vivenciaram juntos põem em cena conflitos emocionais típicos da infância, e, nesse ínterim, oferecem ao jovem leitor ferramentas subjetivas para seu próprio amadurecimento ético, emocional, psicológico e cognitivo.

\section{Referências}

AZEVEDO, Ricardo. "Literatura infantil: origens, visões da infância e certos traços populares." Disponível em: http://www.ricardoazevedo.com.br/wp/wp-content/uploads/Literatura-infantil.pdf. Acesso em: 06 set. 2019. Publicado in: Presença Pedagógica, Belo Horizonte, Editora Dimensão, n. 27, mai./jun. 1999 e em Cadernos do Aplicação, v. 14, n. 1⁄2, Universidade Federal do Rio Grande do Sul, jan./ fev. 2001.

BETTELHEIM, Bruno. A psicanálise dos contos de fadas. Tradução de Arlene Caetano. Rio de Janeiro: Paz e Terra, 2002.

BIRMINGHAM, David. Breve história da Angola moderna: séculos XIX-XXI. Lisboa: Guerra \& Paz, 2017. 
CANDIDO, Antonio. "O direito à literatura". In: CANDIDO, Antonio. Vários escritos. São Paulo: Duas cidades; Ouro sobre azul, 2004. p. 169-191.

COELHO, Nelly Novaes. Literatura infantil: teoria, análise, didática. São Paulo: Moderna, 2000.

CORSO, Diana Lichtenstein; CORSO, Mário. Fadas no divã: psicanálise nas histórias infantis. Porto Alegre: Artmed, 2006.

COSTA, Germano Quintanilha. A criança, o adulto e o infantil na psicanálise. Disponível em: http://www. psicanalise.ufc.br/hot-site/pdf/Trabalhos/31.pdf. Acesso em: 07 set. 2019.

COSTA, Terezinha. Psicanálise com crianças. Rio de Janeiro: Zahar, 2010.

FERNANDES, Maria Celestina. "Surgimento e desenvolvimento da literatura infantil angolana pósindependência." Disponível em: https://www.ueangola.com/criticas-e-ensaios/item/301-surgimentoe-desenvolvimento-da-literatura-infantil-angolana-p\%C3\%B3s-independ $\% \mathrm{C} 3 \% \mathrm{AAncia}$. Acesso em: 26 ago. 2019.

FREUD, Sigmund. "Análise da fobia de um garoto de cinco anos." In: FREUD, Sigmund. Obras completas - volume 8: O delírio e os sonhos na Gradiva, Análise da fobia de um garoto de cinco anos e outros textos (1906-1909). Tradução de Paulo César de Souza. São Paulo: Companhia das Letras, 2015.

FREUD, Sigmund. “O escritor e a fantasia." In: FREUD, Sigmund. Obras completas - volume 8: O delírio e os sonhos na Gradiva, Análise da fobia de um garoto de cinco anos e outros textos (1906-1909). Tradução de Paulo César de Souza. São Paulo: Companhia das Letras, 2015.

FREUD, Sigmund. "Três ensaios sobre a teoria da sexualidade." In: FREUD, Sigmund. Obras completas - volume 6: Três ensaios sobre a teoria da sexualidade, Análise fragmentária de uma histeria ("o caso Dora") e outros textos (1901-1905). Tradução de Paulo César de Souza. São Paulo: Companhia das Letras, 2016.

HUNT, Peter. Crítica, teoria e literatura infantil. Tradução de Cid Knipel. São Paulo: Cosac Naify, 2010.

KLEIN, Melanie. "Some theoretical conclusions regarding the emotional life of the infant". In: KLEIN, Melanie. Envy and gratitude and other works (1946-1963). London: Vintage, 1997.

LAJOLO, Marisa; ZILBERMAN, Regina. Literatura infantil brasileira: história \& histórias. São Paulo: Editora Ática, 2007.

MUNANGA, Kabengele. África - Trinta anos de processo de independência. Revista USP, n.18, 1993. p. 100-111.

ONDJAKI. A bicicleta que tinha bigodes. Rio de Janeiro: Pallas, 2012.

ONDJAKI. Os transparentes. São Paulo: Companhia das Letras, 2013.

PALO, Maria José; OLIVEIRA, Maria Rosa D. Literatura infantil: voz de criança. São Paulo: Editora Ática, 2006. 
Submissão: $11 / 04 / 2020$

Aceite: $25 / 07 / 2020$

https://doi.org/10.5007/2176-8552.2019.e73280

Esta obra foi licenciada com uma Licença Creative Commons Atribuição-NãoComercial 4.0 Internacional. 